\title{
UN REY PARA LOS MORISCOS: EL INFANTE DON JUAN DE GRANADA
}

\author{
Valeriano Sánchez Ramos*
}

\author{
"Los descendientes de los infantes don Juan y don \\ Hernando tienen por apellido de Granada, y traen por \\ armas dos granadas en campo azul, y un letrero \\ atravesado que dice Lagaleblila, que quiere decir: \\ "no hay vencedor sino Dios" \\ (Luis del Mármol Carvajal)
}

Los acontecimientos vividos en el reino de Granada bajo los Reyes Católicos -la conquista y su posterior etapa mudéjar-, pese a los vacíos que de hecho existen, están perfectamente desvelados en sus líneas básicas ${ }^{1}$. En cambio, al día de la fecha quedan todavía lagunas importantísimas sobre la época morisca, desenlace final de muchos de los entramados elaborados en la etapa precedente. Dentro del periodo, el alzamiento de 1568 es, sin ninguna duda, el punto culminante, por cuanto fue el desenlace final de muchos puntos marcados desde la toma de Granada.

La rebelión del reino reinició algunos de los engranajes creados por aquellos protagonistas de finales del siglo $\mathrm{XV}$, los cuales volvían a desempolvar viejos métodos de colaboración y colaboracionismo ${ }^{2}$. Aunque -también al igual que entonces- las diferencias que envolvían el complejísimo equilibrio morisco salpicaban por doquier.

Uno de aquellos nudos gordianos afecta a la propia familia real granadina, concretamente a los descendientes de los hijos del rey Muley Hacen ha-

* Grupo de Investigación “Repobladores y Moriscos”. Universidad de Granada.

1. Baste citar dos nombres: M.A. LADERO QUESADA, con dos obras esenciales: Castilla y la conquista del Reino de Granada, 1987, y Granada después de la conquista. Repobladores y Mudéjares, Granada, 1988; y A. GALÁn SÁnCHEZ, Los mudéjares del Reino de Granada, Granada, 1991.

2. Para comprender algunas de las líneas del entramado morisco en el Reino, antes y durante la contienda, vid. V. SÁNCHEZ RAMOS, «Los moriscos que ganaron la guerra», Melanges Louis Cardaillac, Zaghougan (Túnez), 1995, tomo II, pp. 613-627 y B. VINCENT, «Et quelques voix de plus: de Francisco Núñez Muley à Fatima Ratal», Sharq al-Andalus, 12, 1995, pp. 131-145. 
bidos con la esclava Zoraya o Turayya, pues la sublevación de 1568 los convirtió en protagonistas esenciales de un episodio nada conocido. La azarosa historia de estos infantes de Granada está perfectamente desvelada en sus líneas maestras a través del admirable estudio de López de Coca. Gracias a este trabajo reconstructivo podemos comprender el complejo entramado de propósitos y despropósitos que envolvieron a los nasríes en sus últimos años ${ }^{3}$.

El seguimiento posterior de los príncipes Sa'd y Nasr, al igual que el de su descendencia, prácticamente es desconocido, aun cuando -como queda dicho- la guerra de los moriscos los puso en el candelero. Puede que el conflicto granadino les quedara lejos, pero, quizás sin saberlo $y$ tal vez sin quererlo, eran quienes eran y la guerra -como cualquier otra guerra- no entendía de medias tintas.

Los sucesos que vamos a relatar, al igual que en su día hiciera el maestro López de Coca, se basan en la reconstrucción minuciosa de un interrogatorio realizado en Milán en plena guerra de los moriscos sobre los infantes de Granada ${ }^{4}$, así como la correspondencia que distintos oficiales regios en Italia realizaron en torno a ellos. Los documentos históricos descritos no trascendieron más allá de los despachos filipinos, convirtiéndose en una información reservada que fue tratada como un "asunto de Estado", prácticamente mantenido en secreto hasta la actualidad. Mucho, pues, de lo que se expone en este trabajo tiene que ver con el complejo servicio de espionaje de Felipe II y su organizada trama por mantener su equilibrado sistema internacional. Un mundo casi desconocido, pero que rigió el enmarañado imperio y formidable "Mundo Mediterráneo" del que nos hablara Braudel. Los espías del rey, con sus aciertos y desaciertos, observaciones y previsiones, pueden abrir sorpresas como la que relatamos ${ }^{5}$.

3. J.E. de COCA CASTAÑER, «Granada en el siglo XV: Las postrimerias nazaríes a la luz de la probanza de los infantes Don Fernando y D. Juan», Actas del V Coloquio Internacional de Historia Medieval de Andalucía, Córdoba, 1988, pp. 599-641.

4. A.G.S., Estado, leg. 1224, p. 75. El documento lleva por título exacto: «Ynformaçion que se hizo en Milán sobre la fuga de don Juan de Granada». En adelante, siempre que citemos este documento, sólo aludiremos a las respuestas emitidas por los interrogados y los folios donde se encuentran. En el original está sin foliar, la foliación es nuestra.

5. Los más interesantes estudios sobre el espionaje son todavía pocos, remitiéndonos a los siguientes: 1) Con respecto a la etapa cronológica que trabajamos, vid. C.J. CARNICER GARCíA y J. MARCOS RIVAS, Sebastián de Arbizu, espia de Felipe II. La diplomacia secreta española y la intervención en Francia, Madrid, 1998. 2) Sobre el tema concreto de espionaje, vid. E. Sola y J.F. de la PEÑA, Cervantes y la Berbería (Cervantes, mundo turco-berberisco y servicios secretos en la época de Felipe II), Madrid, 1996. 3) Aunque alejado cronológicamente, no queremos dejar de citar -por lo que tiene de interés metodológico y sugerentes líneas de trabajo- la obra de D. SALINAS, Espionaje y gastos en la diplomacia española (1663-1683), Valladolid, 1994. 


\section{PARTE. "LOS ANTECEDENTES"}

\section{UNOS SÚBDITOS MUY ESPECIALES: LA FAMILIA REAL NASRÍ}

A partir de 1492 en el reino de Granada sólo cabía una posición de poder: colaborar en los proyectos de los Reyes Católicos. Por ello, la salida de Boabdil en 1493 fue un asunto de Estado que culminó con éxito la carrera de su artífice, el secretario real Hernando de Zafra ${ }^{6}$. La marcha del Rey Chico vino acompañada de un cierto reconocimiento de la realeza de sus hermanos, los infantes de Granada.

En efecto, los príncipes S'ad y Nasr eran los eternos rivales de su hermano Boabdil desde que Muley Hacen en 1478 se encaprichara de su madre, a quien le entregó gran parte de las herencias de sus tías, las princesas Çetti Onfalfata y Çetti $\mathrm{Haxa}^{7}$. De hecho, en 1490 los hermanos de Boabdil se presentaron como recambio regio, inquietante noticia que inclinó a los Reyes Católicos por secuestrarlos y enviarlos a Sevilla ${ }^{8}$. Tuvo mucho que ver en aquel asunto Çidi Yahya al Nayar -miembro de una rama real nasrí contraria-, personaje clave a partir de entonces en el reino de Granada, puesto que se erigió en el representante de la colaboración con los Reyes Católicos?.

Bautizados en fechas muy cercanas a la toma de la ciudad, ambos príncipes recibieron el sacramento -según una crónica granadina del siglo XVII- bajo el signo regio:

"[....] Pusiéronle Çad, el mayor, don Fernando de Granada, por el Rey Católico que fue su padrino, y al menor le pusieron don Juan de Granada, respeto del príncipe don Juan que lo apadrinó. Diéronle palabra de que se les daría el estado de Mondexar, que era suyo en Las Alpuxarras, abiéndose conquistado, y ellos desto se les hiço otras muchas merçedes" ${ }^{\prime \prime}$.

Puede decirse que en 1492 la descendencia de Muley Hacén quedaba eternamente dividida: mientras que su primogénito, el rey Boabdil, se mantenía musulmán y alejado del reino de Granada, sus hijos menores eran cris-

6. M. GASPAR y REMIRO, «Partida de Boabdil allende con su familia y principales servidores», Revista del Centro de Estudios Históricos de Granada y su Reino, 2, 1912, reedición facsímil en la misma revista, núm. 18 (2 época, 1990), pp. 58-59.

7. J.E. LÓPEZ de COCA CASTAÑER, «Granada en el siglo XV...», p. 601.

8. $\quad$ Ibidem, p. 635 .

9. Hijo del infante Ibn Çelim, era nieto del rey Yusuf IV Vid. M. EsPINAR MORENO y J. GRIMA CERVANTES, «Un personaje almeriense en las crónicas musulmanas y cristianas. El infante Cidi Yahya Alnayar (1435?-1505)», Boletín del Instituto de Estudios Almerienses, 7, 1987, pp. 57-83 y, de los mismos autores, el «Testamento y muerte de D. Pedro de Granada», Mayurqa, 22, 1989, pp. 239-254.

10. F. HENRíQueZ de JorquerA, Anales de Granada, Edición facsímil con estudio preliminar de Pedro Gan Giménez, Granada, 1987, tomo I, p. 434. 
tianos y cercanos a la corte de los Reyes Católicos. La madre de estos últimos también se bautizó poco tiempo después con el nombre de D. ${ }^{a}$ Isabel de Granada, seguramente por influencia de la reina Católica, a quien acompañó en la corte hasta su muerte.

El feliz desenlace sólo se rompió con la vuelta a Granada de un miembro real, el destronado sultán meriní Abu Zayyan, casado con la tía de los infantes. Este inconveniente, empero, se solucionó positivamente, pues el noble musulmán y su esposa terminaron por bautizarse con el nombre de D. Fernando y D. ${ }^{a}$ Isabel -seguramente por el padrinazgo de los Reyes Católicos- e igualmente acabaron desempeñando importantes labores de colaboración. El estatuto real de D. Fernando de Fez le permitirá colocarse en una posición de preeminencia moral y protocolaria entre la comunidad morisca, al mismo nivel que la rama real contraria ${ }^{11}$.

Con la salida de la familia real nasrí allende, los infantes disfrutaron de algunas rentas sueltas, símbolo que identificaba su realeza ${ }^{12}$, si bien los Reyes Católicos las cambiaron por un juro de un cuento y cuatrocientos mil maravedíes y la tenencia del castillo de Monleón, en Galicia $^{13}$. La intención era clara: primero, tenerlos alejados de Granada y evitar su contacto con la población mudéjar. Segundo, preservarlos como elemento de recambio -o cuando menos de discordia- en caso de que en tiempos futuros la familia real nasrí reclamase nuevamente el trono.

A partir de 1495, en el reino de Granada sólo se admitía la sumisión de la casa real o la colaboración. Los infantes de Granada representaban el primer papel, mientras que la línea real contrincante de Çidi Yahya y su hijo, bautizados como D. Pedro y D. Alonso de Granada-Venegas, participaban de la segunda vía. En ambas posturas los nasrís eran literalmente súbditos de Castilla, nobles y de esclarecido linaje, pero al fin y al cabo súbditos. El nuevo estatus generará en ellos un ansia integradora que acabará justificando increíbles arboles genealógicos en los que se hacen ver ambas familias como descendientes de los godos que recuperaban su antigua fe. Incluso los tratadistas identificaron a la sultana Soraya como cristiana, una tal D. ${ }^{a}$ Isabel de Solís, y a su hermana aún la presentaban como esposa del cabeza de la línea real contraria ${ }^{14}$.

11. M. J. RUBIERA MATA, «La familia morisca de los Muley-Fez, príncipes meriníes e infantes de Granada», Sharq al-Andalus, 13, 1996, p. 163.

12. M.A. LADERO QUESADA, «La repoblación del reino de Granada anterior a 1500», Hispania, 110, 1968, p. 535.

13. L. del Mármol Carvajal, Historia del Rebelión y Castigo de los moriscos del Reino de Granada, Málaga, 1599, ed. facsímil de la publicada por la B.A.E., con estudio preliminar de A. Galán Sánchez, Málaga, 1991, p. 50.

14. E. SORIA MESA, «Una versión genealógica del ansia integradora de la elite morisca: el Origen de la Casa de Granada», Sharq al-Andalus, 12, 1995, pp. 213-221. 
En conclusión, y en palabras de López de Coca, con el Zagal y Boabdil en Berbería y Granada-Venegas (a los que por nuestra parte añadiríamos los Fez-Muley), cuyos derechos sucesorios basados en la línea femenina carecían de respaldo, una posible restauración nasrí era prácticamente imposible ${ }^{15}$. Los únicos verdaderamente con legitimidad para reclamar el trono de La Alhambra eran los infantes de Granada y, convertidos en súbditos leales de Castilla, pasaba por impensable.

\section{LOS INFANTES DE GRANADA AL SERVICIO DE LA MONARQUÍA}

Los infantes de Granada y su madre continuaron en todo momento la ruta de los Reyes Católicos: entre 1504 y 1505 residen en Segovia, Salamanca y Valladolid. Como cualquier otro noble del momento, aparecen asegurando sus posesiones en Granada a través de copias de escrituras arábigas que D. Fernando de Mendoza solicitaba en 1506 ante las autoridades de la ciudad $^{16}$. Totalmente mimetizados en la sociedad del momento, en los albores del siglo XVI, ambos infantes se encontraban casados con importantes linajes castellanos, tan destacados como los del condestable de Castilla: D. Hernando de Granada había enlazado con D. ${ }^{a}$ Mencía Sandoval y de la Vega, señora de Tordehumos, Castrillo, Guardo y Castejón (partido de Medina de Río Seco), nieta del Adelantado de Castilla D. Gómez de Sandoval; mientras que D. Juan de

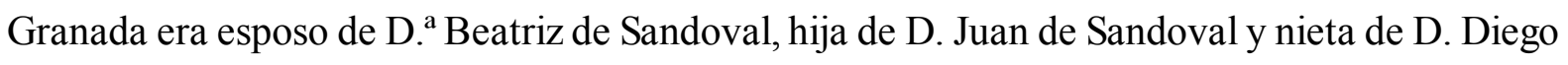
de Sandoval, conde de Castrogeriz. Este último enlace le emparentó con la familia real nasrí contrincante, pues Cidi Yayha había casado en segundas nupcias con D. ${ }^{a}$ Elvira de Sandoval, también nieta del conde de Castro ${ }^{17}$.

D. Hernando de Granada no dejó descendencia y murió tempranamente, en 1512, en Burgos; enterrándose en el monasterio vallisoletano de Ntra. Sra. de Prado, del que era protector. D. Juan de Granada heredó las tierras y señoríos de su hermano y tuvo una vida más larga, convirtiéndose en un colaborador nato de la monarquía. En efecto, con motivo de la guerra de las Comunidades este personaje presidió la "comunidad de Valladolid", logrando controlar a los sectores más exaltados. El episodio no escapó con los años a las defensas que diversos personajes harán de los moriscos sobre su adhe-

15. J.E. LÓPEZ de COCA CASTAÑER, «Granada en el siglo XV..», p. 635.

16. El cálculo de los bienes dejados por el rey Muley Hacén se estima en algo más de 816.000 pesantes. Vid. A. MAlPiCA Cuello y C. TRILlo SAN José, «Los infantes de Granada. Documentos Árabes Romanceados», Revista del Centro de Estudios Históricos de Granada y su reino, 6, 1992, pp. 361-421, en especial 371-374.

17. A. LóPEZ de HARO, Nobiliario genealógico de los reyes y títulos de España, Madrid, 1622, tomo II, p. 107 y ss. 
sión a la monarquía, tales como Núñez-Muley y el cronista Mármol Carvajal ${ }^{18}$. Pese a que este tema se escapa a nuestro trabajo, la participación o no de los moriscos en las Comunidades sería necesario analizarla, pues -al igual que hacía el infante en Castilla- en un punto más delicado como el reino de Granada había moriscos que se alineaban en el mismo bando regio, tal es el caso de Diego López Abenajara, quien capitaneó un cuerpo de 1.000 hombres para aplastar las comunidades de Baza y Huéscar ${ }^{19}$.

Sea como fuere, la labor del infante en Valladolid le valió el reconocimiento regio, materializado en dos cosas: en primer lugar el matrimonio de su hija D. ${ }^{a}$ Magdalena de Granada con el nieto del rey de Portugal, D. Luis de Alencastre, Gran Maestre de la Orden de Avis, hijo del duque de Aveiro, noble filohispano ${ }^{20}$. En segundo lugar, su designación como gobernador del reino de Galicia, tierra en la que tenía algunas rentas. Durante su gobernación gozó de la total confianza del emperador, desarrollando importantes reformas en la audiencia gallega, todas ellas tendentes a insertar definitivamente el poder central contra la reacia nobleza, alineada con las comunidades $^{21}$.

D. Juan de Granada tuvo larga descendencia, pues, a la muerte de su esposa, casó en segundas nupcias con D. ${ }^{a}$ María de Toledo y Monzón, dejando de ambos enlaces larga progenie ${ }^{22}$. El hijo mayor fue D. Juan de Granada, Caballero de Santiago que enlazó con D. ${ }^{a}$ Beatriz de Velasco y Mendoza, hija del virrey de Méjico y de D. ${ }^{a}$ Juana de Castilla ${ }^{23}$. Por esta última, su esposa era nieta de D. Sancho de Castilla, noble cuyos señoríos estaban en el reino de Granada, concretamente la villa de Gor y la taha de

18. J.E. LÓPEZ de COCA CASTAÑER, «Granada en el siglo XV...», p. 604.

19. V. SÁNCHEZ RAMOS, «Los moriscos que ganaron...», p. 619.

20. Joao de Alencastro, duque de Aveiro, es uno de los miembros del séquito portugués que acompañó al príncipe D. Juan (futuro D. Juan III) a España con motivo de su matrimonio con la infanta D. ${ }^{a}$ Catalina, hermana del emperador. Vid. J. MARTínEZ MILLÁN, «La familia real y los grupos políticos: la princesa

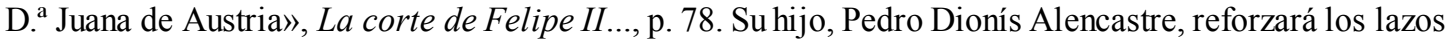
con la parentela del infante, al casar con una miembro de la Casa de los Condes de Cifuentes y de Portalegre. Vid. F. Bouza ÁlvareZ, «Corte es decepción. Don Juan de Silva, Conde de Portalegre», La Corte de Felipe II..., p. 471, nota 82.

21. L. Fernández VegA, La Real Audiencia de Galicia, órgano en el Antiguo Régimen (1480-1808), La Coruña, 1982, tomo I, p. 138.

22. Del primer matrimonio nacieron, entre otros, D. Juan, Gerónimo Bernardino, Isabel y Magdalena de Granada y Sandoval, esta última casada con D. Luis Alencastre, nieto del rey de Portugal y Gran maestre de la Orden de Avis. Del segundo matrimonio nacieron Diego, Pedro, María y Felipa Granada y Toledo, las dos últimas monjas en Santo Domingo el Real de Madrid.

23. Apuntes biográficos de la familia en M.J. SARABIA VIEJO, Don Luis de Velasco, virrey de Nueva España (1550-1564), Sevilla, 1978. 
Alboloduy ${ }^{24}$. El primogénito de D. Juan no dejó descendencia, por lo que todos sus derechos dinásticos pasaron a su hermano.

\section{JUAN Y D. HERNANDO DE GRANADA Y MENDOZA EN ITALIA}

Al morir su hermano sin descendencia, D. Gerónimo Bernardino de Granada y Sandoval se convirtió en la cabeza familiar. Estaba casado con D. ${ }^{a}$ Cecilia de Mendoza, hija del conde de Castro, D. Carlos de Mendoza, hermano del Adelantado de Galicia, D. Diego Hurtado de Mendoza. Este enlace lo adscribía a la nobleza gallega representada por la casa de Ribadavia e, igualmente, lo conectaba nuevamente con la nobleza granadina, puesto que un tío de su esposa era D. Enrique Enríquez el de Baza, por matrimonio con D. ${ }^{a}$ Francisca de Sarmiento ${ }^{25}$.

D. Bernardino sólo dejó dos varones: D. Juan y D. Hernando de Granada Mendoza, nacidos a finales de la década de los años treinta o primeros de la siguiente. Muerto casi al nacer sus hijos, todos los derechos dinásticos de D. Bernardino recalaron en el mayor de la casa, D. Juan de Granada. Ambos infantes se educaron en Alcalá de Henares y anduvieron por la corte en Toledo, mientras que su madre -ya viuda- permanecía en Valladolid ${ }^{26}$. Será en la ciudad imperial del Tajo donde ambos hermanos -especialmente D. Juan- entablen amistad con un soldado, Antonio Sánchez. Como él mismo dice: “[...] en Toledo le començe a conosçer, porque ally le dy leccion de la scrima" ${ }^{27}$. Esta relación se mantendrá muy estrecha con el paso de los años, como más adelante veremos.

A mediados de los años sesenta, coincidiendo con el nombramiento del duque de Alburquerque como gobernador de Milán, D. Juan marcha a su lado, quedando entretenido como asistente con un sueldo de 20 escudos.

24. Este linaje era descendiente de la Casa real de Castilla, una reconstrucción del mismo y sus posesiones en el reino de Granada en: E. SORIA MESA, Señores y oligarcas: los señoríos del Reino de Granada en la Edad Moderna, Granada, 1997, p. 281 y M. GóMEZ LORENTE, «Los señoríos en el Reino de Granada: el señorío de Gor», Cuaderno de Estudios Medievales, 14-15, 1985-1987, pp. 61-74.

25. Ambos eran hijos de D. Juan Hurtado de Mendoza y D. ${ }^{a}$ María Sarmiento, hija del Adelantado Mayor de Galicia, D. Bernardino de Sarmiento, conde de Ribadavia. Vid. J. GARCÍA OrO, «La nobleza gallega en el reinado de Felipe II», en A. EIRAS RoEL (coord.), El Reino de Galicia en la Monarquía de Felipe II, Santiago, 1998, p. 308. Para un acercamiento a la familia Sarmiento vid. del mismo autor: D. Diego Sarmiento de Acuña, conde de Goadomar y embajador de España (1567-1626). Estudio biográfico, La Coruña, 1997.

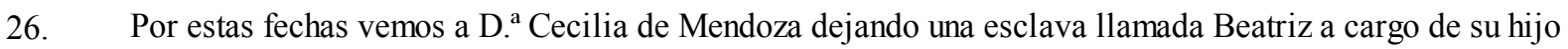
D. Juan, con el ánimo de libertarla a los 7 años y entregarle 50 ducados. Vid. Luis FERNÁNDEZ MARTín, (S.J.), Comerciantes, esclavos y moriscos en Valladolid. Siglos XVI y XVII, Valladolid, 1988, p. 147.

27. Respuesta de Antonio Sánchez, fols. 4v.-5r. 
Tiempo después -en pretensión de hacer igual carrera- le sigue su hermano D. Hernando, quien, alrededor del mes de noviembre o diciembre de 1568, embarca en Cádiz en un galeón de Benito Rodríguez y desembarca en Liorna ${ }^{28}$, entrando a servir en la guarnición de Asti bajo el mando del capitán Gonzalo de Salinas. En tierras italianas ambos hermanos disfrutan de las amistades de los mejores generales del momento, entre ellas la de su paisano D. Luis Quijada, señor de Villagarcía, persona de total confianza de la casa real como tutor de D. Juan de Austria ${ }^{29}$.

Junto con la más alta nobleza, los infantes gustan de otras amistades menores. Por ejemplo, en este tiempo los hermanos vuelven a coincidir con su profesor de esgrima, Antonio Sánchez, quien se encuentra destacado en Milán. La antigua amistad se refuerza muchísimo, especialmente con D. Juan, como comenta el propio soldado “[...] despues viviendo yo en Milán le hallé en él aquí, donde he estado en su compañía dende que vine habrá un año, y por ser mi amigo me dava una cama en la estançia donde estava" ${ }^{30}$. Corre el año 1567 y otra amistad, esta vez más peregrina, es fundamental en la vida del infante: la relación que en Plasencia comienza a tener con un soldado llamado Chaves, también destacado como él en esta plaza italiana. La característica que destaca al soldado es que "[...] él estuvo en Constantinopla esclavo mucho tiempo, y que se escapó de allá él y otros en una fregata, y estando don Juan en Plasencia le halló ally en el castillo, que servía de soldado" 31 .

La amistad del biznieto de Muley Hacén con una persona que había estado "mucho tiempo" en la capital del imperio turco -enemigo mortal de España- sí era motivo de alerta. Entre otras razones porque la experiencia decía que gran parte de los cristianos que cayeron en manos turcas perdieron de su fe y se convirtieron en musulmanes, ingresando así en el grueso número de "renegados". Unos renegados -dicho sea de paso- que en muchos casos volvieron a sus tierras de origen y sirvieron de espías para la Sublime Puerta ${ }^{32}$. ¿Acaso es descabellado pensar esta posibilidad? Desde luego para el gobernador de Milán no pasaba desapercibida.

Pese a la distancia, la comunicación de los hermanos con España es fluida, no sólo por sus propias idas a la Península sino por la constante correspondencia con su madre, cartas en "[...] las quales contenían cosas entre padres e

28. Respuesta de D. Hernando de Granada, fol. 16r.

29. Una breve biografía del mismo, en C. PÉREZ PICÓn, «Don Luis Méndez Quixada, Presidente del Real Consejo de Indias», en El Consejo de Indias en el siglo XVI (D. Ramos, ed. Valladolid, 1970), pp. 89-109.

30. Respuesta de Antonio Sánchez, fols. 4v.-5r.

31. Respuesta de Antonio Sánchez, fol. 3v.

32. Un acercamiento al tema en Bartolomé y Lucile BENNASAR, Los cristianos de Alá. La fascinante aventura de los renegados, Madrid, 1989. 
hijos y que nos embiavan nuestros terçios acostumbrados" 33 . Junto a estos dos medios, algunos compañeros de armas que vuelven a la Península también ayudan a transmitir información fresca. Una de aquellas noticias era la inquietud que en 1568 tenía D. Juan por volver a España, aludiendo para ello diferentes causas. La más expresada ante D. Beltrán de la Cueva era visitar a su esposa, pues, como advierte su propio hermano, “[...] tenía entendido gustar a su excelencia y holgarse que se fuesse, por yr como yva a su casa a casarse y hazer vida con su mujer, que no lo contrario. Ymaginándome yo ésto, entendí que para obra tan buena y sancta, que su excelencia le diera ayuda y favor (para partir a España) y se lo aconsejara y mandara por fuerça, por ser su excelencia tan cristianíssimo como es, por haver estado tanto tiempo sin juntarse con su mujer"34. Corría el último trimestre del año 1568, fecha clave para el reino de Granada y aun para esta peculiar familia, como ahora veremos.

\section{PARTE. "LOS HECHOS: LA REBELIÓN MORISCA DEL REINO DE GRANADA”}

\section{EL ALZAMIENTO DE LAS ALPUJARRAS Y EL BIZNIETO DEL REY MULEY HAZEN}

El hijo mayor de la dinastía, D. Juan de Granada, a la altura de 1569 era descrito por los italianos como un "[...] moço de edad de 25 años, con poca barba, grande de cuerpo [...]"35. Todos coincidían en que "[...] éste era -a my parezer- cavallero y la cara lo denotava modo de venticuatro años, barba roxa, hombre delicado, de buena estatura" ${ }^{36}$. Aunque alguno lo hacía de más edad: “[...] era mançevo blanco con poca barba, roxa, de çerca de treinta años" ${ }^{37}$. En suma, hombre joven, entre 25 y 30 años, de buena estatura, tez blanca y pelirrojo.

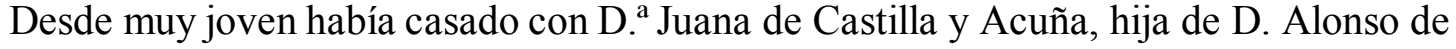
Castilla y D. a Inés de Acuña. Durante sus servicios en Italia, la esposa queda en Valladolid, aunque es visitada con cierta regularidad por D. Juan. No obstante, a finales de 1568 el matrimonio se verá afectado por la sublevación de los moriscos del reino de Granada, pues tal evento era evidente que les atañía grandemente.

33. Respuesta de D. Hernando de Granada, fol. 16v.

34. Respuesta de D. Hernando de Granada, fol. 12r.

35. Respuesta de Angelus de Penutis, fol. 22v.

36. Respuesta de Vicente de la Cabaletta, fol. 10r.

37. Respuesta de Baltasar de Barretis, fol. 23r. 
No sabemos si los moriscos granadinos pensaron en el nieto mayor del príncipe Nazar como su rey, pero las circunstancias lo rodearon para que fuera el punto esencial de una increíble historia. Las disensiones entre los sublevados por encontrar una cabeza que los uniese no escapaban al análisis de la monarquía hispana y, desde luego, aún menos las observaciones sobre la legitimidad potencial del infante de Granada. En la mente de los granadinos todavía estaba impresionado el primer momento de la pascua de 1568, cuando El Albaicín se negó a abrir las puertas a Farax ben Farax, quien les demandaba su apoyo para coronarse. Aún en el mes de enero de 1569 la ciudad de la Alhambra recibía noticias desconcertantes sobre las enormes disputas que en Beznar protagonizó este morisco tintorero con los Valoríes alpujarreños, por coronar como rey al hijo de D. Antonio de Córdoba y Válor ${ }^{38}$. La razón era descender de los califas de Córdoba (de ahí el apellido de la ciudad de la mezquita), quien acabó coronándose con el nombre de Muley Mahamete aben Humeya (Omeya) ${ }^{39}$.

No sabemos cuándo pudo llegar la noticia del alzamiento a Italia, pero da la coincidencia que D. Juan de Granada expresa al duque de Alburquerque su interés por ver a su mujer en la fecha de la sublevación. D. Beltrán de la Cueva se niega a algo que antes le agradaba. En los primeros meses del año 1569 D. Juan vuelve a intentarlo, aduciendo esta vez la necesidad que tiene de curarse en su tierra de una enfermedad. El gobernador de Milán reitera su negativa.

Desde España, D ${ }^{\text {a }}$. Cecilia de Mendoza -siempre atenta a los sucesos granadinos- no dudó en los primeros meses de 1569 en enviar cartas a sus hijos para informarles de la sublevación y rogarles que no se moviesen de Italia. El consejo materno especialmente se acentuaba con su hijo mayor, pues si bien él estaba enfermo y deseaba volver a la casa familiar "[...] ella le havia escrito que estando muy malo, como él le dezia, se podía partir por amor de la salud, aunque de otra manera se holgava más que estuviesse fuera de Spaña mientras durava lo de Granada" ${ }^{40}$.

Entre tanto, el alzamiento morisco continuaba conformándose, siendo la organización de sus cuadros de mando la que interesaba en aquel momento. Mientras que en el sector occidental alpujarreño la figura de Aben Humeya adquiría predicamento, en otras regiones del reino aún se dudaba de él. En efecto, había grandes sectores moriscos que seguían desconfiando de la familia Umeya y preferían decantarse por la familia real nasrí. Bien es cierto que los únicos miembros que podían tener a la mano era la línea des-

38. V. SÁNCHEZ RAMOS, «La guerra dentro de la guerra: los bandos moriscos en el alzamiento de Las Alpujarras», Actas del IV Congreso Internacional de Mudejarismo, Teruel, 1998.

39. L. del Mármol CARVAJAL, Historia del Rebelión..., p. 94.

40. Respuesta del capitán D. Alfonso de Villarroel, fol. 30r. 
tronada del infante Çidi Yahya al Nayar, a quien en la figura de D. Alonso Avis Granada-Venegas los moriscos de la zona oriental de Almería le ofrecieron la corona de sus antepasados; toda vez que a un pariente suyo, D. Alonso de Bazán Hazén, también se le ofertó el cargo de general ${ }^{41}$. En suma, la falta de un líder nato para la rebelión morisca era vox populi.

El escaso concenso para entronizar a un rey de los moriscos seguía inquietando a la viuda de D. Bernardino de Granada. Por ello, a finales del primer trimestre de 1569 volvía a reiterar su convicción de advertir a sus hijos que se mantuvieran en Italia. Su comunicante esta vez fue un compañero de ambos hermanos, el capitán D. Alfonso de Villarroel, quien de paso para su tierra visitó en Valladolid a D. ${ }^{a}$ Cecilia de Mendoza. En aquel encuentro esta dama expresó al militar el enorme riesgo que rodeaba la vuelta de su primogénito: “[...] porque le dezian que los moriscos de Granada buscavan a otros que eran menos parientes de sus hijos para hazerlos cabeça, lo qual me dixo la dicha señora el mes de março passado quando yo bolvia en Italia, diziéndome, sy bien me acuerdo, que yo lo dixesse assy a don Juan, su hijo, paresçiendole que hasta que lo de Granada fuesse acabado estarían bien por acá en Italia, y assy yo luego que llegué a Milán lo dixe al dicho don Juan, y él me dixo entonçes que holgava de hallarse por acá, y que quando se hallara en España fuera para servir a su magestad"42.

Pese a que Villaroel comunicó con D. Juan, éste seguía empeñado en volver a España. En estos delicados momentos aparece de nuevo la figura del soldado Chaves, quien se desplaza de Plasencia a Milán al lado del infante. Como comenta D. Hernando de Granada, pese a tener una curiosa biografía, la estancia con su hermano nada tenía de particular, pues “[...] Chaves era soldado en el dicho castillo de Plasençia, y de ally le truxo my hermano por ruegos que le hizo que le llevasse en Spaña. Y particularmente lo que oy dezir es que él fue esclavo en Constantinopla muchos días, y después él y otros cristianos levantaron una fregata o vergantin en que se salvaron, habrá como quatro o çinco años, de lo qual llevava sus fees y recaudos. Y por ser hombre pobre y no tener con que yr a Spaña para dar quenta a Su Magestad de este serviçio rogó a my hermano le llevasse consigo"43.

\section{UN DESEO IMPOSIBLE: LA MARCHA DEL INFANTE A ESPAÑA}

Durante el primer trimestre de 1569 -y pese a los ruegos contrarios de su madre- D. Juan de Granada no deja de pedir a D. Beltrán de la Cueva el

\footnotetext{
41. V. SÁNCHEZ RAMOS, «Los moriscos que ganaron...», pp. 622-623.

42. Respuesta del capitán D. Alfonso de Villarroel, fol. 30r.-v.

43. Respuesta de D. Hernando de Granada, fol. 14r.
} 
permiso para marchar a España, recibiendo siempre la misma y taxativa negativa. A finales de la primavera de 1569 , un nuevo hecho pone sobreaviso a las autoridades españolas del Milanesado. Así declaraba en agosto el Auditor General de Guerra: “[...] en el presidio de Aste fue preso pocos meses ha un turco por la sopecha que se tuvo de que venía con algun trattado, [...] que el dicho turco está todavia preso y que por lo que contra él resulta se le han dado diversos tormentos, y que entre otras cosas que ha confessado ha dicho que haya çiertas comissiones de algunos moros de Spaña"44. En realidad era un renegado cristiano de Palermo que fue capturado el 24 de mayo de 1569 y de su confesión se supo que se llamaba Francisco Mariano y era hijo de Francisco de Calabria y Magdalena de Túnez. Su interrogatorio lo mantenía en secreto el gobernador de Milán ${ }^{45}$.

Mucha coincidencia era que en torno a los infantes recalasen personajes vinculados a los otomanos: primero, la amistad de D. Juan con el soldado Chaves. Segundo, un renegado al servicio del Gran Turco aparece en el presidio que sirve D. Hernando. Para Alburquerque todo ello era algo más que suerte...

¿Acaso los moriscos granadinos querían contactar con D. Juan de Granada a través de los turcos? Las fechas desde luego son coincidentes con la reactivación de la guerra que Aben Humeya planteaba a través de los otomanos. Desde marzo su hermano Luis de Válor, conocido como Abdallá Humeya, era embajador en Argel y más tarde en Constantinopla, si bien sus tratos no son del todo $\operatorname{conocidos}^{46}$. Las relaciones entre turcos y moriscos a lo largo de la primavera se materializaron en el verano con un importante pacto a través del gobernador de Túnez ${ }^{47}$. Entre los acuerdos alcanzados se encontraba la ayuda militar otomana en armamento y asesores militares $^{48}$. ¿Habría que conectar el apresamiento del renegado en el presidio de Asti con una nueva estrategia morisca?

Como reconocía Felipe II a finales de noviembre al duque de Alburquerque, el renegado capturado en Asti advertía la relación entre los cristianos nuevos de los reinos de Granada y Valencia, peligrosa bolsa de moriscos que -caso de sublevarse- ponía en serio aprieto a las tropas

44. Pregunta del interrogatorio a Antonio Sánchez, fol. 5r.

45. A.G.S., Estado, leg. 1224, p. 46.

46. Luis CABrera DE CÓRDOBA, Historia de Filipe II. Rey de España, Madrid, 1876, tomo II, p. 562.

47. Son fundamentales los contactos entre el general morisco Hernando el Habaquí y el bey Aluch Alí a mediados de agosto. Vid. V. SÁNCHEZ RAMOS, «La guerra dentro de la guerra...».

48. A. GALÁN SÁNCHEZ, «Turcos y moriscos en la rebelión de Las Alpujarras: algunas notas sobre la guerra de Granada de 1568-1570», Actas del II Congreso Nacional de Historia Militar, Málaga, 1993, pp. $129-136$. 
reales $^{49}$. La información del prisionero permitió comunicar a los capitanes generales de ambos reinos que tomasen medidas extraordinarias, así como a D. Luis de Requesens, pues “[...] se ha analizado lo que dijo el moro en Haste y, aunque tiene tan bariable que se puede tomar poco fundamente dello, todavía por lo que dize del trato que tuvo con aquel morisco veynticuatro de Xativa y con otros de Granada, me ha parecido avisar de ello al ilustrísimo D. Juan de Austria, mi hermano, y al Conde de Benavente, para que lo tengan entendido y hagan la diligencia necesaria, y también al Comendador Mayor, para que sepa del moro que es de la galeras de Guillem de Rocafull"s0.

Con el renegado preso en Asti y sus preocupantes declaraciones, las ansias de D. Juan por marchar a España aumentaban. Con ellas Alburquerque extremaba su vigilancia y, por supuesto, su negativa a la partida. Las conversaciones entre D. Beltrán de la Cueva y D. Juan de Granada quedan resumidas perfectamente así: “[...] su excelencia le dixo que no le conbenia yr a Spaña estando las cosas de Granada en los términos que están, sin dar quenta al señor Luis Quixada. Y que respondiendo el dicho don Juan que Luis Quixada estava lexos del rey. Que el duque le dixo que escriviese a algún amigo suyo en la corte. Y que don Juan respondió que no tenía amigo. Y replicándole el duque que los de su casa hazian este offiçio y assi mesmo su excelencia escriviría por él a quien don Juan quisiesse y que lo pensasse y otro dia dixesse a su excelencia lo que en esto quería hazer, para que lo favoresçiere y ayudasse con ello" ${ }^{\text {. }}$.

Era evidente que el infante sabía que su amigo y paisano, D. Luis Quijada, estaba al lado de D. Juan de Austria en Granada, pues -como comenta el cronista Luis del Mármol- "[...] a 6 días del mes de abril partió don Juan de Austria de los jardines de Aranjuez, donde había ido a besar las manos a su magestad y a despedirse para proseguir su camino, llevando consigo a Luis Quijada; y tomando postas por jornadas moderadas, llegó en seis días a la villa de Hiznaleuz (Iznalloz), que está cinco leguas de Granada"52. Por las mismas fechas que entraba su paisano Quijada en Granada, el infante tenía conocimiento -como el resto de la población italiana- de la movilización de los tercios para la guerra de los moriscos. El aludido cronista debió venir con el primer contingente, concretamente en las compañías de Piamonte, Nápoles y Lombardía, las cuales desembarca-

49. Pese a sus años, sigue estando en plena vigencia el trabajo de S. GARCÍA MARTínEZ, «Bandolerismo, piratería y control de moriscos en Valencia durante el reinado de Felipe II», Estudis, I, 1972, pp. 85-167.

50. A.G.S., Estado, leg. 1224, p. 122. Carta de Felipe II al duque de Alburquerque. Madrid, 26 de noviembre de 1569 .

51. Pregunta expuesta a Antonio Sánchez y al infante D. Hernando de Granada, fols. 2r.-v. y 12v., respectivamente. 
ron con $\mathrm{D}$. Luis de Requesens en tierra peninsular a últimos de mayo ${ }^{53}$. Pese a la más rotunda realidad, el gobernador de Milán seguía negando lo evidente. ¿Qué podía pensar D. Juan de Granada ante lo innegable? ¿Cómo se atrevía a decir al gobernador de Milán que no conocía a nadie para escribir, cuando en su genealogía aparecían apellidos de rancio abolengo como Sandoval, Velasco o Mendoza?

Italia entera sabía de la guerra de los Moriscos, pero los virreyes, gobernadores y embajadores españoles destacados en la península apenina respondían al mismo patrón estratégico: la rebelión era pequeña e insignificante, estaba a punto de concluirse y no merecía la pena desplazarse a España. Un ejemplo meridiano es Fernando Gonzaga, marqués de Castiglione, quien, enterado en esta población cercana a Milán del alzamiento morisco, pretendía servir al rey. El propio gobernador de Milán con una admirable diplomacia volvió a negar lo evidente, resumiendo perfectamente en fechas posteriores al rey la política seguida en los estados italianos con respecto al tema granadino: “[...] convendría mucho, más si fuesse possible, que ningún hombre Bella (Italia), en esta occasión ni en otras, pasasse a Spaña, pues, bolviendo por acá, son éstos los que más daño hazen con su naçion, que toda es de la calidad que por otra he dicho a Vuestra Magestad" ${ }^{54}$.

Era lógico que admitir la debilidad española en su propio territorio sólo podía traer, cuando menos, problemas. Máxime cuando desde la primavera de 1569 Felipe II había ordenado a su embajador ante Pío V que restableciese con Roma la organización de una coalición antiotomana $^{55}$. ¿Era consciente D. Juan de la alta política regia? ¿Qué estaba pasando en el reino de Granada para tanta negativa del gobernador de Milán? ¿D. Juan no podía haber hecho sus propias cábalas sobre la situación granadina? ¿Qué sabía el infante sobre toda la situación mediterránea?

Sólo escapaban a la cerrada salida española algunos nobles italianos de indudable fidelidad. Un caso era el genovés Pelegrán Doria, quien acompañaba a D. Juan de Austria en su campaña granadina y que en la toma de Galera se hizo famoso por el disparo que sufrió, siendo merecedor de citas de los cronistas de la guerra: “[...] a Pagán de Oria, hermano del príncipe Juan Andrea de Oria, de otro (disparo) que le pasó los dos muslos" ${ }^{25}$.

53. V. SÁNCHEZ RAMOS, «El mejor cronista de la guerra de los moriscos: Luis del Mármol Carvajal», Sharq al-Andalus, 13, 1996, pp. 236-237, pequeño capítulo que dedicamos a "Luis del Mármol y los tercios de Italia".

54. A.G.S., Estado, leg. 1226, p. 31. Carta del duque de Alburquerque a Felipe II. Milán, 28 de febrero de 1570 .

55. M. RIVERO RODRÍGUEZ, «El servicio a dos cortes: Marco Antonio Colonna, almirante pontificio y vasallo de la monarquía», en J. MARTínEZ MiLláN, La corte de Felipe II, Madrid, 1994, p. 337.

56.

G. PÉREZ de HitA, La guerra de los moriscos, Edición facsímil de la editada por Paula Blanchard-Demouge con estudio preliminar de J. Gil Sanjuán, Granada, 1998, p. 249. Este 


\section{PARTE III. "LA TRAMA"}

\section{LOS PREPARATIVOS PARA LA HUIDA A ESPAÑA}

A finales de julio de 1569 D. Juan de Granada tiene decidido marcharse a España, y aprovechando la ida de Antonio Sánchez a Asti para cobrar su paga, le rogó que hablase con su hermano. De la entrevista entre ambos amigos, D. Hernando reconoce que "[...] él me dixo de parte de my hermano como se quería yr en Spaña, y esto me lo dixo a boca, trattando conmigo algunas cosas particulares" ${ }^{\prime 7}$. No sabemos más, aunque conocemos el interés de D. Juan de Granada por charlar personalmente con su hermano. Está decidido a marchase a España, sea como sea.

En la misma fecha y con idéntico motivo que Sánchez, viajaba a Asti Salcedo, criado de D. Juan, quien entregó a su hermano una carta. Como reconoce D. Hernando de Granada, “[...] lo que contenia la dicha letra es que, vista aquella, partiesse para Milán, porque estava determinado yrse a Spaña y pedir a su excelencia me diesse su plaça o me entreteniesse conforme a la calidad de my persona. $\mathrm{Y}$ en deffetto que su excelencia no tuviese quenta dehazerme merced, me fuesse con él" ${ }^{\prime 58}$. Para evitar problemas, la misiva la mostró el infante a su alférez Ruy Gómez y a D. Rodrigo de Castro "[...] lo uno por darles parte de mis negocios, lo otro por venir en la carta encomendadas para ellos" $" 59$. ¿Querían ambos hermanos de alguna manera evitar sospechas de su encuentro en Milán? ¿Tal vez hicieron ver otra cosa?

A principios de agosto D. Hernando de Granada se desplaza a Milán para encontrarse con su hermano, advirtiendo la negativa de D. Beltrán a permitirle marchar y concederle la sustitución de la plaza. D. Juan debe explicarle sus planes para irse a España y le insta a que le acompañe. D. Hernando de Granada comprende a su hermano pero no se marchará de Italia. Luego dirá a las autoridades españolas que " [...] es verdad que él me escribió que quería yr luego en Spaña y con toda brevedad, pero no dezia secretamente. Y dezía que era para effetto de disponer y tratar de los negoçios de su hazienda “60 ¿ ¿Era esto verdad o, por el contrario, es lo que D. Hernando debía o pretendía decir?

mismo hecho lo recoge M. Gómez-Moreno en los apéndices, sobre un manuscrito de la Academia de la Historia, a su edición de la Guerra de Granada de Diego Hurtado de Mendoza, Memorial Histórico Español, Madrid, 1949, tomo XLIX, p. 221. Igualmente lo refiere L. del MÁRMOL CARVAJAL, Historia del rebelión..., p. 218.

57. Respuesta de D. Hernando de Granada, fol. 15r.

58. Ibidem, fol. $15 \mathrm{v}$.

59. Ibidem, fol. 16r.

60. Ibidem, fol. $15 \mathrm{v}$. 
Para D. Hernando, la celeridad en la marcha de su hermano era disponer sus asuntos económicos, pues según las declaraciones de varios testigos se advierte que D. Juan de Granada no se encontraba muy boyante. A esta apreciación se suma las de sus criados: Antonio Sánchez advierte que los problemas de liquidez de D. Juan obligaban al secretismo, "[...] por temor de sus acreedores no le impidiessen la yda, porque entendiendo que él se querría partir, como ya lo havia publicado, venieran muchos a demandarle sus créditos" ${ }^{\text {"61 }}$. Simón de Mucis, responde lo mismo: “[...] yo le havia oydo dezir otras muchas vezes que quería hazer aquel viaje a effetto de casarse, [aunque] antes me suspeché que [....] me ymaginé que huviesse venido a my casa porque sus acreedores no se fatigasse" 62 .

¿Quiénes eran estos banqueros que tanto angustiaban a D. Juan? Según su criado, “[...] los mercaderes que le davan dineros eran los Negrones, los quales solían estar en la calle de San Pedro Lorto, y que agora están junto al Cavallero Aretin, y que assimesmo le dava Peligro Doria, el qual está a San Lorenço, la vía por donde era de Spaña"63.

Si el infante no tenía dinero, ¿cómo podía partir a España? En principio D. Juan pensó en viajar junto al conde de Cifuentes, quien preparaba su marcha a España. Al fin y al cabo el aristócrata entraba dentro de la parentela familiar del infante ${ }^{64}$, además de ser amigos desde que ambos residieron en Alcalá de Henares. De aquel ruego del infante, “[...] el Conde le respondió que haviendo buen passaje yría luego. Y de otra suerte que no pensava yr hasta tanto que escriviesse el señor Ruy Gómez le enbiasse una galera, o dos, para su passaje". Por lo que quiera que fuese -tal vez la lentitud de Cifuentes- hace que D. Juan cambie de parecer, pues “[...] dixo que determinava yrse y passar en lo que hallasse. $Y$ en defetto de no hallar passaje yr en una fregata, o en la primera cosa que hallase" ${ }^{25}$. En la búsqueda de un nuevo transporte, nuestro personaje parece que se decide por una fragata tierra a tierra, argumentando la negativa a partir con Cifuentes “[...] porque no dixesse que se yva en compañía del conde porque le hiziesse el gasto" $"$.

61. Respuesta de Antonio Sánchez, fol. 2r.

62. Respuesta de Simón de Mucis, fol. 19v.

63. Ibídem, fol. 20r.

64. El hermano de Cifuentes era el conde de Portalegre, marido de la prima del infante, D. ${ }^{a}$ Beatriz de Mendoza y Lasso de la vega, hija del D. Álvaro de Mendoza, II conde de Castro, y D. a Ana de la Cerda, tíos de D. Juan de Granada. Además, los portugueses Alencastre -tan cercanos a los infantes- igualmente estaban emparentados con los Silva. Vid. F. BouZA ÁlVAREZ, «Corte es decepción. Don Juan de Silva...», p. 456, en especial nota 15 .

65. Respuesta de D. Hernando de Granada, fol. 13v.

66. Respuesta de Antonio Sánchez, fol. 3r. 
El medio ya estaba solucionado, ahora quedaba costear el pasaje. La falta de liquidez la resolvió el infante contactando a últimos de julio con el banquero Antonio María Vivaldo. El interlocutor elegido ante Vivaldus fue un oficial del duque de Alburquerque, Martín de Alvelda, quien “[...] con larga arenga me rogó y importunó que yo le acomodasse de dozientos escudos a cambio para Spaña, que allende me quedaría en grandíssima obligación y me daría por seguridad algunos gentiles hombres españoles en quien yo me contentasse" ${ }^{\text {"67 }}$. El dinero se entregaría cuando lo pidiese D. Juan.

Resuelto el último problema a principios del mes siguiente, la partida a España se fija para la madrugada del domingo 15 de agosto. El día antes D. Juan recibe del banquero Vivaldi 200 escudos “[...] a cambio de otros tantos que le ha de dar en Madrid a Lorenzo de Spinola, con más el cambio. Y estos dineros le dio el sabado de mañana, el día antes que se partiesse"68. Es curioso que en la trama financiera para sufragar el viaje de D. Juan se encuentre Peligro Doria, banquero genovés que -como hemos visto en el apartado anterior- tiempo después acompañaba a D. Juan de Austria en su campaña contra los moriscos. El mismo que presionaba al infante por deudas.

Con el dinero en el bolsillo desde la mañana, D. Juan de Granada tiene vía libre para su proyecto. Por la noche charla con su hermano, quien se había trasladado de Asti a Milán a su solicitud, momento en el que ambos charlaron a solas. De aquella conversación todo parece indicar que el gobernador de Milán desconocía la marcha, razón por la cual no quiso pedirle su sustitución en la plaza. Según dijo después D. Hernando de Granada, su hermano le rogó que al día siguiente se entrevistase con el duque de Alburquerque y le comunicase su partida a España. Tras despedirse de su hermano, D. Juan huye del palaçio del gobernador.

\section{EL INTENTO FRACASADO DE HUIDA}

La noche entre el sábado 14 y el domingo 15 de agosto es intensa; mientras que D. Juan de Granada habla con su hermano, su equipaje está siendo trasladado a otro sitio: "[...] hizo enbalisar la ropa que tenía en palacio de su excelencia en dos baules, los guales hizo llevar fuera" ${ }^{69}$. Se trataba de la casa de su criado Simón de Mucis, quien describe perfectamente el desarrollo de las horas siguientes: “[...] don Juan havia ydo a su casa de tres horas de noche, con un paje y dos faquines que llevavan dos caxas y que avia dormi-

67. Respuesta de Antonio María Vivaldus, fol. 27r. Reproducimos en el apéndice documental el fragmento del banquero por cuanto tiene de explicativo de la trama financiera.

68. Respuesta de D. Hernando de Granada, fol. 17v.

69. Respuesta de Antonio Sánchez, fol. 1 r-v. 
do ally"70. Amaneció, pues, el palacio del gobernador de Milán sin el infante de Granada.

Tras dormir unas horas, el domingo 15 de agosto es bastante movido en casa de Simón de Mucis. Por la mañana D. Juan le entrega dinero al criado para que compre comida y busque caballos para su partida, quedando solo en la vivienda. Entre tanto llega a la misma su amigo Chaves, aquél que residió en Constantinopla. A solas conversan, nada se sabe de lo que hablaron. De vuelta, Simón de Mucis anuncia al infante los problemas que hay para encontrar caballos, es domingo y víspera de la virgen: “[...] despues de haver comido el dicho don Juan en compañía de Chaves, mandó a este confesante que fuesse a llamar a Antón Sánchez y assí mermo a buscar cavallos o coche para su partida" 71 . Nuevamente quedan solos en la casa D. Juan de Granada y Chaves. Se desconoce la conversación mantenida.

A las seis o siete de la tarde llega Antonio Sánchez a la casa -ya no está Chaves- y “[...] después de haver hablado con él de cosas, como se suele entre los amigos, se partió" 72 . Eran las 8 de la tarde y acompañaban al infante, además de Simón de Mucis, "dos faquines que le llevaban la ropa hasta la primera hostería fuera de Milán que va a Binasco, en compañía de Antón Sánchez y Salçedo y Jerónimo, sus criados que acompañaban"73.

Llegados “antes del Ave María” a la Hostería La Briosca, a las afueras de Milán y en el camino a Binasco, surge el primer percance del proyectado viaje. Al demandar el infante caballos, el dueño de la hostería, Pedro Ferrari, "le respondió que no tenía cavallos y después de haverle dado de bever a él y a los demás que venían en su compañía, siendo venidos a caso çiertos molineros con dos mulos, se concertó con ellos que le llevassen las valisas y ropa hasta la hostería del Molino Nuevo"74. No pudo conseguir más el infante, por lo que "se fue a pie el dicho don Juan hazia Binasco, haciendo llevar su ropa en dos mulos de un molinero"75. Aquí se despiden Antonio Sánchez y Simón de Mucis, siguiendo solo D. Juan y sus dos criados.

De todas formas, en la ruta entre la hostería La Briosca y el Molino Nuevo, D. Juan cambia de idea y se vuelve a Milán. Quedan en camino el molinero, llevando el equipaje, siguiéndole los criados del infante a pie. ¿Era premeditada esta vuelta? ¿Fueron sólo las circunstancias las que obligan a cambiar de planes?

70. Respuesta de Simón de Mucis, fol. 18v.

71. Ibídem, fol. 19r.

72. Respuesta de Antonio Sánchez, fol. 1v.

73. Respuesta de Simón de Mucis, fol. 19r.

74. Respuesta de Pedro Ferrarius, fol. 21r.

75. Respuesta de Antonio Sánchez, fol. 1 v. 


\section{EL ENCARCELAMIENTO DE D. HERNANDO DE GRANADA}

Mientras D. Juan huía durante el domingo 14 de agosto, su hermano no hacía nada por comunicar con el gobernador, según él decía que habían acordado. Muy al contrario, "[...] aquel día estava en casa del médico, curándome y pensando que venía presto para poder hallar a su excelencia, (si bien) no huvo lugar por ser tarde. Y ansy hablé al señor don Beltrán de la Cueva y le dy un recado de parte de my hermano y dexava para el lunes el hablar a su excelencia"76. Llegada la nota al gobernador, el duque de Alburquerque -en previsión de posibles consecuencias- ordena encarcelar a D. Hernando de Granada. El infante se encontraba cenando en casa del maestro Viçenço. A las 11 de la noche entró en casa del médico el capitán de caballos ligeros Ulibarre, informando a D. Hernando que debía acompañarlo al palacio del gobernador. En las habitaciones del duque le espera el capitán Carvajal, el cual lo traslada a las 6 de la mañana del día 16 de agosto al castillo de Bragassa, donde fue entregado al castellano para su prisión.

El mismo 16 de agosto comenzó el interrogatorio a D. Hernando de Granada. Curiosamente en todo momento negó haber recibido cartas de España en las que se anunciase la rebelión de los moriscos, algo imposible de creer por las declaraciones públicas que hacían su madre y amigos. Igualmente daba a entender que nunca tuvo conocimiento de morisco alguno en Asti, pese a estar destinado en aquella guarnición. De igual modo no pensó que la marcha de su hermano fuera una huida. En fin, todo eran sospechas de primer orden, máxime cuando el servicio secreto español conocía la actividad turca a favor de los moriscos y su proyectado avance por el Mediterráneo a costa de la rebelión granadina ${ }^{77}$.

\section{PARTE. "LA HUIDA DEL INFANTE: DE MILÁN A LIMEDO”}

Casi a la vez que D. Hernando de Granada era encarcelado, su hermano volvía sobre sus pasos desde el camino de Binasco a Milán. En la ciudad, sobre las 11 de la noche, envía a buscar a Lázaro de Olvia, criado del palacio del gobernador, el cual acude "con el criado a Puerta Tosa, donde dentro de la puerta hallamos asentado sólo al dicho don Juan de Granada". Allí le pide que le guíe a casa de algún amigo donde esconderse la noche del domingo. Lázaro declara que "lo llevé a casa de un amigo mío hortelado, el

76. Respuesta de D. Hernando de Granada, fol. 18r.

77. Sobre ello, vid. Abdeljelil TEMIMI, «Le Gouvernement Ottoman face au problème morisque», Les Morisques et leur temps, Montpellier-Paris, 1983, pp. 299-311, y L. CARDAILLAC «Le turc, supreme espoir des morisques», Cahier serie histoire, Tunez, II, pp. 37-47. 
qual esta fuera de la muralla vieja de Milán, junto San Marcos, cabe El Navillo, en una casa blanca. Donde entrando llamé al patrón de la casa, llamado Juan Angelo, el qual estava en el lecho y le rogué que por hazerme plazer quisiesse tener ally en casa por aquel día aquel gentil hombre que yba conmigo, diziendo que era don Juan de Granada y a un criado"78. ¿Sería este criado Chaves? ¿Pudo entrevistarse con él en Puerta Tosa, momento en el que quedó solo el infante?

Según el hortelano, Angelo de Vayanis, eran las doce y media de la noche y allí estuvo el infante con su criado, "del qual no se partió en todo el día hasta tres o quatro horas, de noche, que le traxeron dos cavallos, el uno blanco y el otro no me acuerdo de qué pelo, y cavalgando en uno dellos el dicho gentil hombre se partió en compañía de aquel que havía traydo los cavallos, siguiéndole a pie su criado"79. ¿Quién trajo los caballos a D. Juan? ¿no sería Chaves?

Poco después, don Juan -ya sin el caballista desconocido- se dirije con Lázaro de Olvia a casa del conde de Cifuentes, aquél con el que no quiso irse a España, entrevistándose con éste a deshoras. La conversación que mantienen ambos hace que a las 5 de la mañana el conde se dirija al palacio del conde de Brocardo, quedando D. Juan en la puerta. Los condes tienen una conversación a solas en los aposentos particulares del noble italiano, tras la cual éste ordena a su criado, Vicente de la Cabaletta, que acompañe a Bergamo a un caballero español, "el cual estava aguardando a la puerta vestido de ropas de villano o molinero, y hablado el dicho conde (Cifuentes) se partió. Y a que el otro (D. Juan de Granada) que ya he dicho, ordenándome que cavalgase en un cavallo de aquellos y le siguiesse, subiendo él en el otro, yendo con él a pie otro criado (Simón de Muciis), se encaminó la buelta del Navillo que va a Gorgonhola. Y entrando en una casa grande y nueva que está junto al Navillo se apeó y desnudó los vestidos de molinero y se vistió otros" $"$.

En el trayecto, el criado del conde de Brocardo observó que D. Juan y Lázaro de Olvia "hablavan en secreto". Tan sólo sabe que el "gentil hombre me dixo que havía dexado otros criados y ropa fuera de Milán, quatro millas hazia Binasco" 81 y a tal destino se encaminaron. Entre tanto, volvieron a parar, concretamente en la casa donde habían estado horas antes. Allí se mudaría D. Juan y pasaría el día de la Asunción. Comenta el criado del conde de Brocardo que en esta casa les esperaba una persona "que estava en ella aquella noche, era hombre viejo y no creo que la casa sea suya" ${ }^{" 2}$. Se trataba

78. Respuesta de Lázaro de Olvia, fol. 25v.

79. Respuesta de Angelo de Vayanis, fol. 24v.

80. Respuesta de Vicente de la Cabaletta, fol. 7r.

81. Ibidem, fol. 8v.

82. Ibidem, fol. 10v. 
de Angelo de Vayanis, el hortelano amigo de Lázaro de Olvia que había permitido que pasasen la noche allí.

Durante la mañana de la Asunción, y antes de volverse a Milán, Lázaro de Olvia tiene que resolver el problema del equipaje. La persona que encontró era un familiar del hortelano de Casa Magna, Baltasar de Barretis "cuñado, molinero, el qual es vezino del señor de la casa, donde el dicho don Juan estuvo a rogarle" 83 . Entre tanto marcha el molinero con la ropa, ambos viajeros esperan la noche. A las tres y media de la madrugada Vicente de la Cabaletta vuelve con caballos, en los que " [...] en uno dellos el dicho gentil hombre se partió en compañía de aquel que havia traydo (Vicente de la Cabaletta) los cavallos, siguiéndole su criado (Lázaro de Olvia)" ${ }^{\prime \prime 4}$.

Continuando el camino, amanece el día de San Roque y los viajeros acuerdan detenerse para no ser vistos, decidiendo hospedarse en el mesón Val de Ambrosia. No obstante, un nuevo infortunio descubre parte de su huida: El dueño de la hospedería, Angelo de Penutis, se encontraba de viaje, razón por la cual su mujer no quería hospedar a los viajeros. El escándalo que sigue permite generar nuevos testigos, pues, como describe Penutis, "se pusieron a querer entrar por fuerça y, acudiendo los vezinos, que con buenas palabras persuadieron a my mujer que los dexasse por aquella noche alojar" 85 .

Según la versión del dueño de la hostería “" [...] assi estuvieron en my casa çinco personas con dos valisas, las quales havian traydo ciertos molineros, y después de haver çenado los dos dellos se partieron, restando tres otros en casa, diziendo que aquellos dos que se partieron dixeron a su mujer que el dia siguiente pagarian el gasto" $"$.

Con ropas distintas D. Juan de Granada decide continuar su camino hacia Bérgamo. Tras despedirse de Lázaro de Olvia, marcha sólo con Vicente de la Cabaletta, siguiéndoles a distancia los criados Salcedo y Jerónimo. El servidor del conde de Brocardo describe perfectamente el trayecto realizado: “[...] y assy despues de averse despedido el dicho gentilhombre de su criado nos partimos para Gorgonçola y sin detenernos passamos adelante, siguiendo nuestro viaje hasta Vergamo. Y assi llegamos a Adda y allí, entrando en la barca, passamos de la otra parte, sin dar çevada a los cavallos ny parar porque el dicho gentil hombre llevaba grande miedo, o que fuesse preso o muerto, porque muchas vezes se tapava la cara y los ojos por no ser conosçido quando se encontraba con alguna persona" ${ }^{\prime 7}$.

83. Respuesta de Lázaro de Olvia, fol. 26r.

84. Respuesta de Angelo de Vayanis, fol. 24v.

85. Respuesta de Angelus de Penutis, fol. 22r.

86. Ibidem, fol. 22r.

87. Respuesta de Vicente de la Cabaletta, fol. 7v. 
Llegados a Bérgamo, los viajeros se hospedan en el burgo, en Ganassa. Después de descansar, Cabaletta decide volver a Milán, ha cumplido su cometido. D. Juan le ruega "que no dixesse a nadie nada de cómo le havia acompañado, ny dexado en Vergamo, diziendome que menos lo huviese de dezir al conde Brocardo, pero que diesse una letra que él escrivió al conde de Cifuentes. Mandándome assi mesmo que abisasse a çiertos sus criados, que yo encontraría en el camino, cómo quedava en Bergamo en la dicha hostería" 88 .

En este punto del viaje se pierde la pista de D. Juan. Sólo sabemos que llegó a las dos de la mañana a la hostería de La Ripa, donde descansó -como queda dicho- hasta la mañana. Por las declaraciones de Cabaletta, el huido le dio a entender que su ruta era ir a Génova: "[...] y él me dixo que se quería yr a Bressa, y hoy que él demandó al mesonero de Bressa en quanto tiempo se podía yr a Génova y quantas millas se passavan por el Estado de Milán"89. No obstante, según el dueño de la hostería, Francisco Monte, tras despedirse del "caballante" (Vicente Cabaletta), D. Juan y sus dos criados "...se partieron, yendo hazia un lugar llamado Limedo, por donde se va a los confines de Veneçianos" $"$. Por tanto, quería que se entendiese la ruta contraria. ¿Qué contenía la carta de Cifuentes? ¿no podría ser una nueva argucia del infante por distraer la atención?

El viaje que realiza D. Juan se asemeja al itinerario recomendado por un texto aljamiado del siglo XVI para que los moriscos abandonasen España y pasasen a los dominios turcos. Entre los consejos para huir, el documento aconsejaba lo siguiente: “[...] demandares el kamino de Milán. -D'allí adelante dires ke is a besitar el señor Sa'Marko de Beneçia. Embarkaros- es en Padua $\mathrm{i}$ en un rrio para Beneçia [...] alli los ke bereys kon tokas blankas son Turkos, los ke bereys kon amarillas son Judios merkaderes del gran Turko. Ad akellos demandareys kuanto kerreys, k'ellos os enkaminaran [...]"'91 • ¿Acaso conocía D. Juan este camino?, ¿era éste el que seguía?...

\section{PARTE. EL DESENLACE: "LA CAPTURA Y PRISIÓN}

\section{DE D. JUAN DE GRANADA"}

Mientras D. Juan huía, el Gobierno de Milán se ponía en guardia. Encarcelado D. Hernando de Granada la noche del 15 de agosto, inició el in-

88. Ibidem, fols. 7v.-8r.

89. Ibídem, fol. 9r.

90. Respuesta de Francisco de Monte, fol. 28v.

91. El manuscrito se encuentra en la Biblioteca Nacional de París, en los "Fondos árabes" y fue publicado bajo el título de «Un itinerario del siglo XVI destinado a los moriscos españoles», Estudios Geográficos, VII, 1946, pp. 136-141. En concreto, el texto citado se corresponde a las páginas 137-138. 
terrogatorio de cuantos habían tenido relación con el infante. La madrugada y el día fueron largos para el auditor general del Ejército, Alfonso Lopecio, y el fiscal general, Gerónimo Marescateo, aunque a últimas horas del 16 de agosto comenzaba a vislumbrarse la trama de la fuga. Con datos en la mano, Alburquerque remitía al rey una carta que no podía ser más alarmante: D. Juan había tomado la ruta hacia Génova, que era como decir el camino a Granada. Lo que puede colegirse de lo siguiente, en plena guerra de los moriscos, es imaginable.

Las medidas adoptadas por Alburquerque eran enérgicas: orden de captura del fugado. Al mismo tiempo desplegaba el formidable dispositivo diplomático español en todo el norte de Italia. En efecto, el 14 de agosto Alburquerque escribía al embajador español en Génova estas palabras: “[...] don Juan de Granada partió de aquí ayer a 3 horas de noche y a lo que se entiende va a la buelta de esta ciudad. Y porque al serviçio de Su Magestad conviene que sea preso el dicho don Juan. Y si no se alcanzara en este estado, le sigan, como así lo he ordenado al teniente Alzola y Antonio Carmona. Y ello se proçede con todo secreto, y con el cuydado y diligençia que vuesa señoría suele poner en todos las cosas que tocan al serviçio de Su Magestad"92. Sobre los perseguidores de D. Juan llama la atención que uno de ellos sea Martín de Alzola, el amigo que días antes había convencido al banquero Vivaldi para que le financiase su viaje.

De las medidas tomadas en Génova para capturar a D. Juan de Granada se da cumplida cuenta al rey el 18 de agosto. Entre ellas, se decía que la Signoria participaba activamente colaborando con el servicio español. Todos estaban ojo avizor en los puertos de la república, especialmente en Sona, La Spezia y la propia Génova, aunque no daban aviso de nada. Así, a finales de mes la embajada ya sospechaba que D. Juan de Granada había tomado la vía de Bérgamo hacia Venecia ${ }^{93}$. De ser cierta la sospecha sobre la ruta hacia la ciudad de los canales, era reconocer la posibilidad de que el infante contactase con la Sublime Puerta. Una probabilidad nada desdeñable, puesto que, desde la misma toma de Granada, el imperio otomano utilizaba esta ciudad como punto de ayuda a los moriscos ${ }^{94}$.

Entre tanto, el gobernador de Milán no dejaba de interrogar testigos. Una pieza clave de su información fue Vicente de la Cabaletta, quien -pese al ruego de infante de no decir nada- pensamos que no dudó en contar a su

92. A.G.S., Estado, leg. 1398, p. 56. Carta del duque de Alburquerque al embajador Figueroa. Milán, 14 de agosto de 1569 .

93. A.G.S., Estado. Leg. 1398, p. 55. Carta del embajador Figueroa a Antonio Pérez. Génova, 28 de agosto de 1569. El fragmento se reproduce en el Apéndice.

94. Míkel de EpalzA, Los moriscos antes y después de la expulsión, Madrid, 1992, pp. 279-283. 
señor, el conde de Brocardo, la ruta seguida por D. Juan. A su vez, Brocardo debió trasladar sus conocimientos a Alburquerque, pues no en balde era un fiel colaborador con la Corona española, al menos desde que en marzo de 1562 se le encargara negociar en Roma para Felipe II el subsidio para 20 galeras ${ }^{95}$.

E1 12 de septiembre -sobre la base de las nuevas declaraciones- el duque de Alburquerque llegaba a la misma conclusión que Génova: D. Juan de Granada perdía su pista en Limedo. Su destino, por tanto, era la tierra veneciana ${ }^{96}$. Dos días después, el rey escribía al embajador de Génova alabando la discreción y diligencia de Alburquerque, toda vez que expresaba su preocupación por que el nieto del príncipe Nars ya estuviera en Granada ${ }^{97}$. La preocupación era, pues, Asunto de Estado.

No obstante, la angustiosa preocupación española llegó a su fin una quincena más tarde, descansando el servicio diplomático español en Italia. Como se desprende de las palabras del embajador en Génova, en contestación a una carta del 3 de octubre al rey, ya se conocía la secreta vía que había seguido el infante para eludir la celosa cerca española, la cual "no será mas nesçessario husarla, pues, por lo que entiendo por carta del secretario Antonio Pérez, havía llegado en Barçelona y el duque de Francavila havia usado la mesma diligencia en mandalle poner en prission. De donde yo tenía siempre por çierto que no podia scapar, por hazer yo tenido aviso que se havia embarcado en esta ribera de levante en un lugar que se llama Setre y muy secretamente, a donde havia venido por vias extraordinarias. Y pues él está allá, y a tan buen recaudo, Vuestra Magestad mandará hazer de él lo que más fuere a su real servicio"98.

¿Qué pasó con aquel Chaves que acompañaba al infante y ahora no aparecía en Barcelona? ¿Qué hizo y con quién trató D. Juan de Granada en el tiempo que estuvo en la ruta hacia tierra de venecianos? ¿Por qué volvió a Génova?, y ¿cómo? Tal vez haya que recordar cómo en Génova también había turcos, manifestándose públicamente como tales, sin miedo a nada $^{99}$. ¿Puede que el infante viniera con ellos a través de alguna vía?

95. J. GOÑ GAZTAMBIDE, Historia de la Bula de Cruzada en España, Vitoria, 1958, pp. 552-553.

96. A.G.S., Estado, leg. 1224, p. 75. El duque de Alburquerque a Felipe II. Milán, 12 de septiembre de 1569.

97. A.G.S., Estado, leg. 1398, p. 225. Felipe II al embajador Figueroa. Madrid, 14 de septiembre de 1569.

98. A.G.S., Estado, leg. 1398, p. 67. Carta del embajador Figueroa a Felipe II. Génova, 6 de octubre de 1569.

99. B. BENNASSAR, «El choque cultural entre cristianos y musulmanes en España, Italia y Francia (siglos XVI-XVIII)», Pedralbes, 15, 1995, p. 29. 
Al final D. Juan de Granada fue capturado en los primeros días de octubre de 1569 en Barcelona, quedando encarcelado por orden de D. Diego Hurtado de Mendoza, duque de Francavilla y príncipe de Mélito, según expresaba el rey personalmente al duque de Alburquerque $^{100}$. Durante octubre y noviembre se interrogó en Barcelona a D. Juan, y de sus respuestas parece desprenderse que todo fue una imprudencia por ir a reunirse con su esposa. Al menos eso hizo ver D. Juan a todo el servicio diplomático español y al mismísimo rey de España, el cual manifestaba tal convencimiento a D. Beltrán de la Cueva: “[...] don Juan acudió a Barcelona, donde por mi orden se le detuvo el duque de Francavillla, con determinación de pasar a Valladolid a casarse, que el exceso que en su salida ha avido ha sido venirse sin vuestra lisensia, y así he mandado escrebir al dicho duque que se le dé licencia para que se vaya a Valladolid a casarse" ${ }^{101}$. La carta regia al gobernador de Milán no podía tener mejor fecha, pues dos días después -el 26 de noviembre- Felipe II ordenaba a D. Juan de Austria levantar un ejército que saliese de la ciudad de La Alhambra para acabar con el problema morisco ${ }^{102}$,

Pese a todo, D. Juan de Granada no dejó de recibir un fuerte susto de Felipe II, como lo comunicaba el rey el 30 de noviembre al comendador Mayor de Castilla, al notificarle la feliz solución de su huida: "[...] y assi he mandado scrivir al de Francavilla que le dé alguna reprehensión por ello, y liçençia y libertad para que se vaya a Valladolid a casarse"103.

\section{EPÍLOGO: EL FIN DE LA MONARQUÍA MORISCA}

Como si los tiempos no hubiesen pasado, y al igual que ocurriera con los Reyes Católicos, mientras que el descendiente de la línea real nasrí contraria, D. Alonso de Granada-Venegas, se desvivía por colaborar activamente con D. Juan de Austria en la pacificación de los moriscos ${ }^{104}$, D. Juan de Granada apuntaba a suceder en la corona de sus ancestros.

100. A.G.S., Estado, leg. 1225, p. 87. Felipe II al duque de Alburquerque. Madrid, 22 de noviembre de 1569.

101. A.G.S., Estado, leg. 1224, p. 122. Felipe II al duque de Alburquerque. Madrid, 24 de noviembre de 1569.

102. V. SÁNCHEZ RAMOS, «El mejor cronista de la guerra...», p. 238.

103. A.G.S., Estado, leg. 910. Carta de Felipe II a D. Luis de Requesens. Madrid, 30 de noviembre de 1569.

104. Vid. E. Soria MESA, «Don Alonso de Granada Venegas y la rebelión de los moriscos. Correspondencia y mercedes de Don Juan de Austria», Cronica Nova, 21, 1993-1994, pp. 547-560. Vid. igualmente Erika SPIVAKOVSKY, «Some notes on the relations between D. Diego Hurtado de Mendoza and D. Alonso de Granada Venegas», Archivum, XIV, 1964, pp. 212-232. 
Felipe II, el infante D. Juan de Granada y D. Alonso Granada-Venegas, los tres nombres que la historia ponía frente a frente, eran los biznietos de aquéllos que intervinieron en la toma de Granada. Como entonces, la situación del reino granadino a sólo admitía la colaboración con el poder, principio y fin del desenlace de la fuga del infante. Cuando todo pasó, como muy agudamente señaló Mármol Carvajal, las posiciones de las dos ramas reales -al igual que en tantos momentos de la historia estamental castellana- serían marcadas diferencialmente con las señas de la heráldica:

"los descendientes de los infantes don Juan y don Hernando tienen por apellido de Granada, y traen por armas dos granadas en campo azul, y un letrero atravesado que dice Lagaleblila, que quiere decir: "no hay vencedor sino Dios", y los que vienen de don Pedro y don Alonso tomaron apellido de Venegas y tambien de Granada. Traen cinco granadas en campo azul. Primero traian una sola, y por un desafío que vencieron padre e hijo en la vega de Granada, en que mataron cinco moros, pusieron cinco granadas y el mesmo letrero" 105 .

Al final, la colaboración de la casa contrincante dio mayores honras y honores en los blasones que la mera sumisión pasiva. Cinco granadas frente a dos es símbolo inequívoco del resultado. No hay duda que los Granada-Venegas acabaron presentándose como interlocutores perfectos entre la Monarquía y la comunidad mudéjar, consiguiendo poseer señoríos en el propio reino de Granada.

Para la Navidad de 1569 -un año después del levantamiento morisco- el infante D. Juan de Granada descansaba en Valladolid junto a su esposa, D. ${ }^{a}$ Juana de Castilla y Acuña, un matrimonio del que no hubo progenie. A su muerte, su hermano D. Hernando de Granada heredó todos sus derechos dinásticos. Casado con D. a Ana del Hierro ("D. 'Ana de Austria”), tampoco dejó descendencia, extinguiéndose con él la dinastía. La desaparición de la última línea directa de la casa real nasrí en España venía a tener un paralelismo con el destierro de los moriscos.

Durante el tiempo que vivieron los infantes en Valladolid, tuvieron que ver cómo los moriscos granadinos se asentaban en la ciudad, formando una numerosa comunidad marginada que acabó igualmente maltratada y vejada hasta su expulsión definitiva con Felipe III $^{106}$. ¿Qué relación -si la

105. L. del MÁrmol CARVAJAL, Historia del Rebelión..., p. 50.

106. Sobre la comunidad morisca de Valladolid, número de asentados, tiempos de llegadas, lugares de destierro, etc., vid. Jean Paul le FLEM, «I.es morisques du Nord-ouest de 1’'Espagne en 1594-1596 après un recensement de l'Inquisition de Valladolid», Mélanges de la Casa de Velázquez, 1, 1965, pp. 223-239; M. Gómez ReNAU, «Contribución al estudio de los moriscos de Valladolid», Al-Qantara, XII, 1991, pp. 181-200 y, de la misma autora, el libro Comunidades marginales en Valladolid. Mudéjares y moriscos, Valladolid, 1993. 
hubo- mantuvieron D. Juan y D. Hernando con los deportados? Preguntas como ésta obligan a estudiar a esta curiosa familia más allá del trabajo que presentamos.

No queremos cerrar este episodio sin citar a los Valoríes, personajes que fueron elevados por los moriscos a la categoría de familia real en sustitución de D. Juan, y cuyo destino final tiene mucho de paralelismo con todo lo descrito. Asesinado el rey Aben Humeya, el resto de su parentela también se disolvió en la sombra de la historia: primero murieron o desaparecieron y, segundo, -los más allegados- acabaron en prisión. En efecto, su padre, D. Antonio de Válor, y su hermano, D. Francisco de Válor, desde 1569 eran prisioneros del rey. Al igual que había ocurrido con los príncipes Sa'id y Nasr en su momento, padre e hijo quedaron desterrados en 1572 en Galicia, reino ya marcado por la historia. De las tierras gallegas ambos escaparon a Portugal, donde en Oporto fueron capturados en enero de 1576, internándolos en dos monasterios de los que no volvieron a salir: D. Antonio en Montederramo (Orense) y D. Francisco en Santos (Lugo). En 1579 D. Francisco de Válor pasó al monasterio benedictino de San Vicente, tomando entre 1583-1584 el hábito y dejando de inquietar al abad ${ }^{107}$.

Aún así, el 15 de mayo de 1583 el propio Felipe II todavía se preocupaba por este peculiar fraile, preguntando al abad de Sahagún la posibilidad de trasladarlo allí. Respondiendo fray Antonio Predo al rey que “...teme que resçibiendo al dicho D. Francisco en dicha casa por religioso podría suçeder quererse volver al Reino de Granada y causar alguna inquietud en los moriscos del reino" "Conocía el infante de Granada el último destino de esta familia? ¿Por qué se eligió Galicia para el destierro?, ¿tal vez la tierra gallega era un ejemplificador recordatorio de la posición que debía mantener el infante? De no ser así, el destino y la historia ofrecen un paralelismo sorprendente. Con el celibato forzado de los últimos Valoríes en España, y la falta de descendencia de los infantes, terminaba de extinguirse cualquier pretendida reclamación al trono de Granada. Sólo la familia real nasrí contraria quedó en pie, la de Cidi Yahya, aquélla que desde antes de la toma del reino optó por colaborar con Castilla, la única que se consolidó en el reino granadino y alcanzó la gracia de un título nobiliario ${ }^{109}$. El clan que suplantó a la familia nasrí, pues, fue el modelo de dinastía regia que necesitaba Granada, y la única que querían los Reyes de España.

107. A. DomíngueZ OrtiZ y B. VInCEnT, Historia de los moriscos, Madrid, 1989, p. 46 y p. 67 y nota 35.

108. A.G.S., Cámara de Castilla, leg. 2187.

109. R.F. Peinado SANTAElla, «Los orígenes del marquesado de Campotéjar (1514-1632). Una contribución al estudio de los señoríos del reino de Granada», Chronica Nova, 17, 1989, pp. 261-279. 


\section{APÉNDICE DOCUMENTAL}

\section{1}

1569, septiembre, 12, Milán

Carta del duque de Alburquerque al rey Felipe II, advirtiendo de las medidas tomas tras la salida repentina del infante D. Juan de Granada.

(A.G.S., Estado, leg. 1224, p. 75)

Su Catholica. Real. Magestad.

D. Juan de Granada, nieto del Infante de Granada, ha estado aquí entretenido muchos meses ha con una plaça de gentil hombre y haviendo, según me han infformado, embiadole a dezir doña Sicilia de Mendoça, su madre, despues del levantamiento de los moros de Granada, que holgava en estremo que en esta sazon y coyuntura él y un su hermano se hallassen en estas partes, por quitar las sospechas y occasiones que podria haver si los dichos moros quissieran ynquirir y saber donde estavan.

No obstante lo que su madre le embió a dezir, me pidió licencia havrá un mes para yrse en Spaña, y conssiderando que en esta resoluçión imprevista podía haver algún inconveniente, siendo materia de tanta importancia y conssideración la que es o puede ser en alguna manera dependiente del dicho levantamiento, le dixe que me paresçia que en ninguna manera le convenía yr a Spaña sin tener orden de Vuestra Magestad. Para ello avisó a Luis Quixada, de quien él dezía que era muy amigo, pues le aconsexaría muy bien lo que en esto devía hazer, y que ansi lo conssiderasse y mirase, y me tornase a hablar en ello. Y haviendome respondido que lo haría acordó de salirse de mi casa una noche sin hablarme palabra, de donde resultó confirmarse mas la sospecha de que en su yda podía haver algún misterio y inconveniente. Y porque, en caso que le huviesse, no quedasse Vuestra Magestad desservido, dí orden para que lo detuviessen y, haviendo él entendido esto, dexó de seguir el camino de Genova, a donde yva encaminado, y yo le havía embiado a prender, y tomó el de Tierra de Veneçianos. Y visto ésto ordené al Auditor General del Exercito y a un Fiscal que resçibiessen informaçión de su fuga y que detuviessen a Don Hernando de Granada, su hermano, que tiene playa de soldado en el presidio de Asti, cuyo examen y de los demás testigos que han tenido alguna noticia desta fuga, va con esta carta, juntamente con un sumario que se ha sacado de un proçesso que aqui se ha hecho contra un moro que fue presso en el dicho presidio de Asti, de cuya deposicion aunque tan variable como por el dicho sumario se verá, consta el trato y comisssión que ha tenido de algunos moriscos de essos reynos, que tanbien ha sido causa para hazerme pensar mas en la fuga del dicho don Juan, aunque no ha dicho ninguna cosa contra él. Si Don Juan huviere paresçido en essa corte, cessaran estas sospechas y se podrá colegir que su partida fue mas fundada en liviandad que en desserviçio de Vuesta Magestad, y hasta tener aviso de lo que Vuestra Magestad manda que en esto se haga estará preso el moro y detenido Don Hernando de Granada, porque no haga otra fuga como Don Juan, su hermano.

Y Guarde Nuestro Señor la Salud Catholica y Real Persona de Vuestra Magestad con acresçentamiento de mas reynos y señorios. De Milan a XII de septiembre de 1569.

\section{S.L.T.R.}

Mgt. Basallo y cryado de Buestra Magestad que las reales manos de bien besa.

El duque de Alburquerque 
1569, septiembre, 15, Milán

Declaración del banquero Antonio María Vivaldo, dando cuenta de cómo se financió la huida del infante D. Juan de Granada.

(A.G.S., Estado, leg. 1224, fol. 27r.-v.)

Yo tenía conosçimiento y ynteligençia con el dicho don Juan de Granada y con su hermano, a causa que me presentaron çiertas çedulas de cambio de çiento y ochenta escudos, los quales no me acuerdo de que parte me viniesse la correspondençia sy no lo viesse primero en el libro. Y esto fue a prinçipio de la venida del dicho don Juan aquí a Milan, con el qual ny su hermano he tenido que hazer otra cosa, salvo que los días passados, quando estava aquí don Diego de Benavides, el dicho don Juan me rogó le diesse quinze escudos, los quales yo le dy por ver que tenía amistad con el dicho don Diego de Benavides, a quien yo conosçía mucho y desseava servir.

Y ahora últimamente, que puede haver quinze o diez y ocho dias, poco mas o menos, hallándome yo en corte con algunos gentiles hombres, vino el dicho don Juan en compañía de Martín de Alvelda, criado de su excelencia, y con larga arenga me rogó y importunó que yo le acomodarse de dozientos escudos a cambio para Spaña, que allende me quedaría en grandíssima obligaçion, y me daría por seguridad algunos gentiles hombres españoles, de quien yo me contentarse. Y por complazerle, atenta su grande instançia, me resolví de darle los dichos dozientos escudos.

Y assy, el día siguiente a buena hora vino a mi casa el dicho don Juan, al qual ordené que se le diessen los dichos dozientos escudos, por un conosçimiento y letra de cambio de otros tantos que él me dexó para pagar en Spaña. Y después que el dicho don Juan se partió, me vinieron letras de Génova, de Filipe Espinola, con una çedula de cambio que venía a Paulo y Peligro Doria, para pagar al dicho don Juan en nombre de su madre çient y ochenta escudos, por letras de Meliá Duce Spinola, dada en Medina del Campo. La qual letra de cambio todavía tengo en my poder, porque haviéndo hablado a Pelegro Doria desta letra de cambio, me respondió que no quería hazer cosa alguna antes de comunicarla con su excelencia.

1569,28 de agosto

Fragmento de una carta del embajador de España en Génova al secretario real Antonio Pérez, informándole de las medidas tomadas por la embajada y la propia Signoría para apresar al infante de Granada.

(A.G.S., Estado. Leg. 1398, p. 55)

[...] A los 18 del presente escriví a vuesa merced con el ordinario de Roma y dí avisso de lo que por acá se ofresçia. Despues acá no me allo con carta de vuesa merced a que deva hazer respuesta, a cuya caussa en ésta no seré muy largo y servirá solamente para dar avisso a vuesa merced como el duque de Alburquerque ha tornado a embiar aquí a Antonio Calmona para que resida en esta çiudad hasta ver si acude a ella don Juan de Granada, por haver tenido aviso que hera ydo la buelta de Vergamo y que podria ser vaxasse a esta çiudad para embarcarse, en la qual ussara de toda diligençia, assi por parte desta Señoría como de la mia, para que viniendo a ella sea presso y llevado a Milán, y tanbien se ha dado orden en La Speçia y en Sona, por parte de esta Señoría, que si acudiere a lli se haga lo mesmo. De lo que suçediere dare avisso a vuesa merçed. 
1570, febrero, 28, Milán

Carta del duque de Alburquerque al rey, informándole de lo conveniente que resultaría que la nobleza italiana no participase en la guerra de los moriscos.

(A.G.S., Estado, leg. 1226, p. 31)

Fernando Gonzaga, marques de Castelionne, me dixo que quería yr a Spaña, y yo le dixe que si él entendía que le convenía yr a algún negoçio particular suyo, hiziesse lo que le pareciesse. Y porque me dixo que quería yr a servir a Vuestra Magestad en la Guerra de Granada, le respondí que para ésto no hera menester que él fuese, dándole a entender con buenas palabras la poca neçessidad que havía de que de Italia fuesse ninguno a hazello en esta ocasión, que no hera sino un levantamiento de algunos moriscos, que con los vassallos de las comarcas lo podía Vuestra Magestad mandar castigar, como ya lo començava a hazer.

Y porque por haver havido algunas difficultades para no hazello podido hazer hasta ahora, era neçesario hazello con alguna mas demostraçion, que es lo mismo que he dicho a todos, porque me paresçe que conviene mucho que se entienda assi en Italia. Y convendría mucho más si fuesse possible que ningún hombre della, en esta occasion ni en otras, pasasse a Spaña, pues bolviendo por acá son éstos los que más daño hazen con su naçion, que toda es de la calidad que por otra he dicho a Vuestra Magestad. Y todavía el dicho Fernando Gonzaga me dixo se resolvia de yr, mostrando voluntad de servir a Vuestra Magestad, cuya su católica y real persona guarde nuestro señor, con acresçentamiento de más reynos y señoríos. De Milán a 28 de hebrero de MDLXX.

\section{ÁRBOL GENEALÓGICO DE LOS INFANTES DE GRANADA}

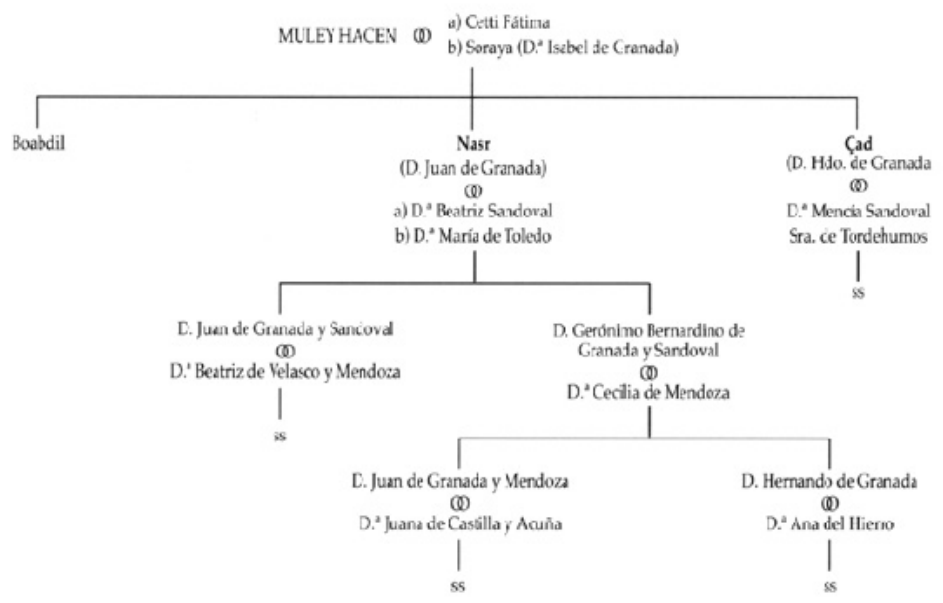




\section{RESUMEN}

En la Navidad de 1568 los moriscos granadinos se sublevan y proclaman el reino musulmán. Uno de los posibles candidatos a rey era el descendiente directo por línea de varón del sultán Muley Hacén, el infante D. Juan de Granada. Destinado en Milán, la cabeza del linaje nasrí fue vigilado por parte de los oficiales de Felipe II, quienes temían que dirigiera las riendas del nuevo estado islámico. La huida inesperada de D. Juan, la persecución posterior; los cruces de información y espionaje, así como las posibilidades dentro del conflicto granadino, convirtieron a este personaje en un asunto de estado. De todo lo sucedido en el interesante año de 1569 y sus repercusiones internacionales, así como la coronación final de un Valorí, da cuenta este trabajo.

Palabras clave: moriscos, Reino de Granada, Milán, Valoríes, Nasríes, espionaje.

\section{ABSTRACT}

A king for the moriscos: the infante D. Juan de Granada. On Christmas Day, 1568, the Moriscos from Granada rose up in arms and proclaim the muslim kingdom. One of likely candidatos to the throne was the direct descendant from the male line from Sultan Muley Hacen, the infante D. Juan de Granada. Established in Milan, the head of the nasri royal line was subjected to surveillance by Phillip Il's men, who feared he might lead the new muslim state. D. Juan's unexpected flight, the subsequent pursuit, the information and spying involved, as well as its implications in the Granada conflict, turned this character into a state affair. This work focuses on the interesting events which took place in 1569 and its international repercussions, including the eventual coronación of a Valori.

Key words: Moriscos, Granada Kingdom, Milan, Valoris, Nasris, spionage. 